\title{
The relationship between tourist nationality, cultural orientation and nature-based tourism experiences
}

\author{
May Kristin Vespestad ${ }^{1 *}$ and Mehmet Mehmetoglu ${ }^{2}$
}

Submitted: 07/06/2010 Accepted: 19/08/2010

\footnotetext{
${ }^{1}$ Research Fellow, Harstad University College, N-9480 Harstad, Norway; e-mail: may.kristin.vespestad@hih.no phone: (+47) 992230 42, fax: (+47) 77058305

${ }^{2}$ Professor, Lillehammer University College, Norway; e-mail: mehmet@hil.no, Phone (+47) 61287473

* Corresponding author
}

\begin{abstract}
This study sets out to explore how tourist nationalities with dissimilar cultural orientation differ in their evaluation of nature-based tourism experiences. For this purpose 679 tourists in Norway responded to a questionnaire on nature-based tourism experiences. Furthermore, 20 nationalities are segmented along a collectivism-individualism continuum (C-I-C). The resulting segments are then compared based on their perception of an overall nature-based tourism experience, which in this study is operationalized in terms of three dimensions; experience, motive and activity. The results show segments that can be divided into high individualism and high collectivism (and a midsegment). The segments diverge significantly on the evaluation of the overall nature-based tourism experience. For instance, the collectivistic tourist nationalities place more importance on entertainment, whereas individualistic tourist nationalities emphasize nature, and more frequently participate in hiking. Additionally, theoretical and practical implications are discussed.
\end{abstract}

(c) 2010 International University College. All rights reserved

Keywords: nature, experiences, individualism, collectivism, cross-cultural comparison

Citation: Vespestad, M.K., M. Mehmetoglu (2010) The relationship between tourist nationality, cultural orientation and nature-based tourism experiences. European Journal of Tourism Research 3(2), pp. 87-104

\section{Introduction}

Internationally, tourism can make an essential contribution to economic recovery, and is acknowledged as playing a vital role in the transformation into a green economy (World Tourism Organization, 2010). In this respect, nature-based tourism experiences evidently can become a significant feature of sustainable development. Nature-related tourism might also initiate funding for conservation as well as raise environmental awareness (Balmford, et al., 2009). Countries promote nature as their primary asset as tourist destinations (e.g. New Zealand, Norway and Scotland), especially by calling attention to the experience aspect of travel. Nature-based experiences have moreover received increased attention from researchers. 
The relationship between tourist nationality, cultural orientation and nature-based tourism experiences.

From a research perspective, the interest in nature-based experiences is escalating (e.g. Mehmetoglu, 2007a, 2007b; Waitt, Lane, \& Head, 2003). The focus on cross-cultural differences in tourism experience consumption, however, is for the most part neglected. In an international tourism context competition is rising, and knowledge of the different markets could be a precondition for success. To create a memorable nature-based experience for international visitors, awareness of how nationality might influence the perception of such experiences is argued essential. In the international tourism arena, the experiential component of holidays is emphasized in promotion material as well as social media. As a result it is essential to know the customers and the national traits that might somehow characterize them.

Providers and marketers of experiences are stakeholders in an international market, and from a managerial point of view the challenge is therefore to know the guests' preferences. Nevertheless, adapting to the guests' needs and wants might not be easy, as experiences are individually perceived and socially consumed. In practice, knowledge of naturebased tourists' national characteristics can result in managerial tools that guide adaptation of nature-based experiences to international tourist demands. Furthermore, knowledge of tourists' experience valuation can provide managers with the opportunity to organize experiences in a way that allows tourists, who are likely to have similar values, to participate at the same time. This could lead to a more coherent nature-based tourism experience from a cross-cultural tourism perspective.

For the purpose of this article, nature-based tourism can be defined as travel to nature areas or destinations (Lang \& O'Leary, 1997). Nature-based tourism experiences are thus defined as those experiences participated in by tourists involved in nature-based tourism. It includes tourism activities with a varying degree of absorption, immersion and participation (e.g. Pine \& Gilmore, 1999). Tourists in nature-based tourism then, move along a continuum in terms of absorption/ immersion and active/passive participation. The study applies a relatively broad definition of nature-based experiences, as it can be argued appropriate in a cross-cultural context, to allow for various understandings of such experiences. This is essential in a crosscultural study, as it requires candour for the differing views on nature, not only those employed by Western frames of reference.

This article attempts to clarify certain aspects of the relationship between national cultural orientation of tourists and nature-based tourism experiences in Norway. The purpose of this study is to segment tourist nationality, based on cultural orientation and then compare the resulting segments in terms of the perception of nature-based tourism experiences.

\section{Literature review}

When people from different countries meet in international tourism, nationality becomes a central issue of interest. The characteristics of tourists from different countries also become evident when tourists come together in naturebased experience production and consumption. Cultural values held by tourists from different nations hence affect tourist behavior and perception, and can furthermore impact experience creation. In an international tourism context then, it is vital to understand culture (De Mooij \& Hofstede, 2010, p. 85), in order to recognize what tourists from various countries emphasize in their holiday experience. People's valuation of nature-based experiences, their motivation for taking part in them, and their preference for activities are therefore likely to differ according to nationality and cultural orientation.

\subsection{Tourist nationality and cultural orientation}

Whether tourists' nationality matters, is debated (e.g. Hsieh \& Tsai, 2009; Lee \& Sparks, 2007). Nevertheless, nationality might indicate some common features of tourists from the same country. It is shown that tourists from one country differ in motivation depending on the visited destination (Kozak, 2002). Nationality might also influence the perception of naturebased tourism experiences because of differing views on nature. Due to the debate of only using nationality as a unit of analysis (e.g. Cayla \& Arnould, 2008), it might be interesting 
to segment nationalities based on their cultural orientation, accounting for the influence of culture. The connection between nationality and cultural orientation is evident (Manrai, Lascu, Manrai, \& Babb, 2001), but not easy or straightforward in its explanation. Cultural orientation is related to general values and represents a common basis of belief. Moreover, cultural orientation is unlikely to be static over time, hence people's way of thinking might move towards or away from each other along a cultural orientation continuum.

Individualism/collectivism is one of several measures used in cross-cultural comparisons and it shows differences in for instance preference for variety (Herrmann \& Heitmann, 2006 , p. 7). Countries can, therefore, be classified in terms of their individualistic or collectivistic orientation. "The contrast individualism/collectivism can be defined as people looking after themselves and their immediate family only, versus people belonging to in-groups that look after them in exchange for loyalty" (De Mooij \& Hofstede, 2010, p. 89). Ones identity in individualistic cultures is in the person, whereas in collectivist cultures the group itself is one's identity, thus it is not about subordinating to the group (De Mooij \& Hofstede, 2010, p. 103).

With respect to tourism nationality and cultural orientation then, tourists' inclination to collectivism or individualism will likely affect their choices. For instance, Western tourists often claim to be independent travelers. There is an expectation in Western societies to be individualistically oriented also in tourismrelated choices, and if one deviates from the norm one will almost have to justify it. Take backpackers as an example, to them being individualistic and traveling alone is a goal in itself, at least it is what they wish to communicate to the surroundings. Nevertheless, when arriving at new places to seek out the unexplored or exotic, it turns out that they often visit the same places, use the same accommodation and become friends with fellow travelers. Their initial goal of being individualistic is replaced by a new form of collectivism (Guneriussen, 2010) in their formation of new enclaves of solo travelers (e.g. Caruana, Crane, \& Fitchett, 2008). Drawing upon this reasoning the following hypothesis should not be far-fetched.

$\mathrm{H} 1$ : There is a relationship between tourist nationality and cultural orientation.

\subsection{Cross-cultural comparisons}

Cross-cultural comparison is carried out on various topics and between different nationalities (Lee \& Sparks, 2007). In tourism research, attention is given to other aspects of cultural and national differences than that which concerns experience consumption. One example is that cultural distance negatively correlates with the intention to visit a destination ( $\mathrm{Ng}$, Lee, \& Soutar, 2007). Others recognize differences in ecotourism between China and the West (Wen \& Ximing, 2008), or how national culture influences service perceptions (Hsieh \& Tsai, 2009). A comparison of tourists of diverse nationalities, and their perception of nature-based experiences, is to our knowledge non-existent.

Comparing nationalities in a tourism context is interesting in terms of how it might indicate differences in the valuation of nature-based experiences. Values are inherent in national cultures, and national culture can be defined as "the collective programming of the mind which distinguished the members of one human group from another" (Hofstede, 1984, p. 21). Furthermore, "via national culture, one can distinguish the difference among groups" (Hsieh \& Tsai, 2009, p. 57). As markets become more global it enhances the need to understand the impact of culture on consumers (Soares, 2004, p. 214), and differences in national cultures can be responsible for many misunderstandings in intercultural encounters (Hofstede \& Hofstede, 2005, p. 114). It is therefore essential to recognize these differences, to meet the challenges brought forth in cross-cultural experiences. Cultural individualism versus collectivism as a dimension of national culture (Hofstede \& Hofstede, 2005) might be a step towards such recognition.

The focus on cultural orientation in this study is not arbitrary, it is in fact argued viable in 
consumer research (Herrmann \& Heitmann, 2006, p. 19) and research demonstrates differences in consumer behavior between collectivistic / individualistic nationalities (Herrmann \& Heitmann, 2006). Consumer research comparing Eastern-European consumers indicates a move towards more individualistic values, as "former collectivist values are gradually being replaced by individualism, but the changes occur at different rates and vary in different market segments" (Manrai, et al., 2001, p. 270). This tendency of former collectivist consumers adopting more individualistic values might also occur in tourism consumption.

According to Steenkamp (2001) the works of Hofstede and Schwartz overlap on the dimensions of individualism/collectivism and conservatism/autonomy, implying that the dimensions explain differences between nationalities, through the relation between the individual and the group. Hofstede (2005, p. 83) indicates several differences between collectivistic and individualistic societies. For one, people in collectivistic societies hold consumption patterns showing dependence on others, as opposed to individualistic consumption patterns showing self supporting lifestyles (op.cit.). Moreover, social network is the primary source of information in collectivistic societies, whereas in individualistic societies media is the primary source of information (Hofstede, 2005, p 97). There is an evident difference then, between collectivistic and individualistic nationalities, and the aim is to examine whether it applies to tourist behavior and perception.

$\mathrm{H}$ 2: Collectivistic and individualistic tourist nationalities differ in terms of their overall nature-based tourism experience.

As can be seen in existing research then, there are arguably differences between nationalities and cultural orientation on the one hand, and consumption and service expectations on the other. It is, moreover, interesting to find out whether it applies to a nature-based tourism context. Such experiences thus need to be operationalized based on the existing literature.

\subsection{Nature-based tourism experiences}

Nature-based tourism experiences are approached from a variety of angles in tourism literature. For instance discussions revolve round motivation (Rhodes Espinoza, 2008), such as escapism (Arnould \& Price, 1993), or learning in relation to e.g. ecotourism (Wen \& Ximing, 2008). Moreover, studies address space construction related to nature-based activities (Preston-Whyte, 2002) and nature tourism constraints (Nyaupane, Morais, \& Graefe, 2004). Besides, a considerable amount of research accounts for ecotourism as a part of nature-based tourism (e.g. Björk, 2000). The discussion of growth in nature-based tourism based on activities such as mountaineering, causing risk to diminish as e.g. knowledge and skills increase (Beedie \& Hudson, 2003), furthermore illustrates features of nature-based tourism experiences. Based on existing literature, the following section elaborates on nature-based tourism experiences consisting of three dimensions; experience, motivation and activity.

\subsubsection{Experience dimensions}

Experiences have become a central issue in the tourism industry (e.g. Mossberg, 2007; O'Dell, 2007), and nature is for many destinations an immense resource in creating experiences. The experience economy (Pine \& Gilmore,1999) often focuses on cultural experiences. Nevertheless, nature-based experiences are evidently a part of it. Experiences will vary individually and across cultures, both in nature- and culture-based experiences. Cohen (1979) refers to five modes of tourist experiences: (1) recreational, (2) diversionary, (3) experiential, (4) experimental and (5) existential. These five modes might form the basis for what an experience is to the consumer, and lead to experiences consisting of feelings such as concentration, absorption, deep involvement, joy and sense of accomplishment (Csikszentmihalyi \& Rathunde, 1993). 
Absorption

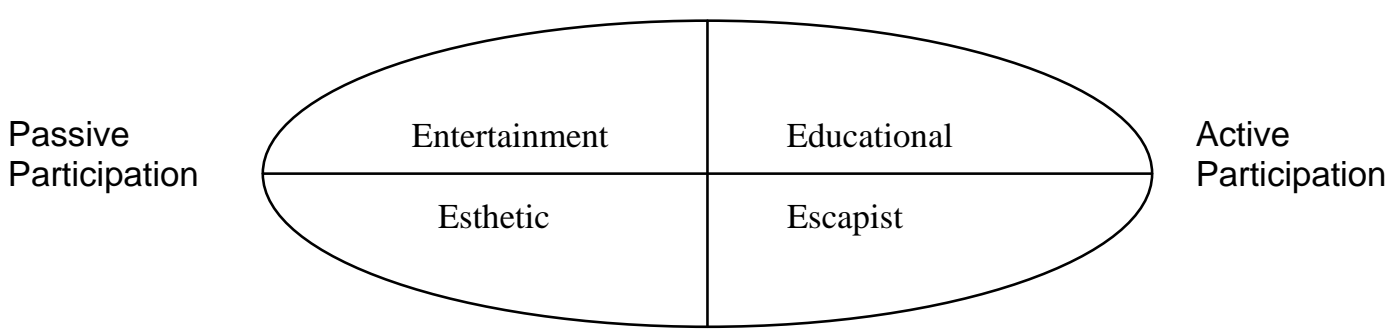

Immersion

Figure 1. The experience realms (adopted from Pine and Gilmore 1999, p.30).

Drawing the attention to the context of naturespecific motivations, Den Breejen (2007) found five factors that affect the long-distance walking experience; (1) enjoyment, (2) intensity, (3) past experience, (4) surroundings and (5) sense of achievement. These factors partly overlap with and expand upon Csikszentmihalyi and Rathunde (1993). An illustration of what experiences are, is seen in figure 1 (adopted from Pine \& Gilmore, 1999, p. 30), where the various elements of the experience are depicted.

More people seem to take an interest in entertainment as an aspect of their lives, especially from the viewpoint of the experience economy. "Entertainment is passively absorbed through the senses" (Pine \& Gilmore, 1999, p. 31 ), it entails time, but does not require specific skills or competences in order to be enjoyed. From a passive aspect then, entertainment represents mere fun and enjoyment, and as such is part of a hedonistic consumer culture, including a social consumption dimension (see Cooper-Martin, 1991). Perhaps passive fun seeking better matches the curiosity of collectivistic nationalities, i.e. countries which have more recently entered into the experience economy. Tourists from countries where entertainment to a greater extent has become an aspect of everyday lives will not emphasize sheer amusement as much in a tourism context, as they have turned their focus towards more active and all-encompassing engagement in experiences. Furthermore, a social consumption of entertainment also supports the presupposition that collectivistic nationalities prefer entertainment.

$\mathrm{H} 2 \mathrm{a}$ : Collectivistic tourist nationalities perceive entertainment as more important than do their individualistic counterparts.

Nature-based experiences also comprise an aspect of learning (Pine \& Gilmore, 1999.p. 13), which might include increased knowledge about a phenomenon or activity. What is more, knowledge seeking is identified as the most important push factor for British tourists traveling overseas (Cheong, Jang, \& Liping, 2002). An individualistic way of thinking implies that learning strengthen the perception of the experience. The interest in knowledge is also identified as important for Westerners in terms of ecotourism (Wen \& Ximing, 2008). Moreover, increased knowledge is an important aspect in individualistic societies.

$\mathrm{H} 2 \mathrm{~b}$ : Individualistic tourist nationalities perceive education as more important than do their collectivistic counterparts.

An escapist experience means that a participant is actively involved and completely immersed in the experience (Pine \& Gilmore, 1999 , p. 33). Highly escapist nature-based tourism experiences can be river rafting, kayaking or mountain climbing (op.cit.). These 
activities can be extraordinary experiences, as they manifest themselves through "harmony with nature, communitas, and personal growth and renewal" (Arnould \& Price, 1993, p. 41), values that seem coherent with an individualistic orientation. The valuation of escapism is expected to be high among individualistic nationalities, as escapism focuses upon the self and personal achievement, through immersion in an experience.

H2c: Individualistic tourist nationalities perceive escapism as more important than do their collectivistic counterparts.

A part of experiences is also the aesthetic aspect (Pine \& Gilmore, 1999), referring to what is aesthetically pleasing to the tourist. Moreover, design has taken on a role in people's everyday lives in individualistic societies. For some, aesthetically pleasing places and nature might offer calm and ease. With reference to experiences then, "an esthetic experience must be true to itself and come off as real to its guests" (Pine \& Gilmore, 1999, p. 38). Landscape could for instance be seen as genuine beauty. Drawing upon the servicescape framework, aesthetics of the physical landscape play a role in differentiating experiences as it creates the actual packaging of the experience (Bitner, 1992). An aesthetically pleasing natural setting will encourage or discourage an activity, as well as influence the competition of drawing people's attention to a nature-based experience. Nature as physical setting then, can either aid or hinder the experience from taking place (op.cit).

\section{$\mathrm{H} 2 \mathrm{~d}$ : Individualistic tourist nationalities perceive aesthetics as more important than do their collectivistic counterparts.}

Whereas an experience can be more or less valued due to its entertainment, educational, escapist, or aesthetic aspect, tourists will also emphasize features of the experience based on the motivation for taking part in it. The following section therefore attends to this dimension of nature-based experiences.

\subsubsection{Motive dimension}

In order to understand what tourists emphasize in nature-based experiences, it is pertinent to look into what might motivate people to take part in those experiences. Push and pull factors are widely discussed in tourism literature and can provide insight into the motivations of international tourists, and might furthermore differ according to nationality (e.g. Kozak, 2002; Mehmetoglu, 2007a; Stilling Blichfeldt, 2007). Prebensen (2006) presents a thorough review of motivation research, and motives are also addressed in terms of push and pull factors in several tourism studies (e.g. Beard \& Ragheb, 1983; Celsi, Rose, \& Leigh, 1993; Crompton, 1979; Galloway, 2002). Crompton (1979) identifies nine motives which influence the selection of pleasure vacation destinations, namely: (1) escape from a perceived mundane environment; (2) exploration and evaluation of self; (3) relaxation; (4) prestige; (5) regression; (6) enhancement of kinship relationships; (7) facilitation of social interaction; (8) novelty and (9) education. The first seven of these motives are socio-psychological and unrelated to destination attributes (Crompton, 1979). Based on former research then, it is reasonable to assume that motives will differ in terms of nationality, as motivations often are attributed to circumstances in the home environment. This is supported by e.g. Kozak (2002), who found that British and German tourists differ on culture, pleasure-seeking/fantasy, relaxation and physical tourist motivations.

Tourists also differ in terms of how their experiences vary along a continuum of individualistic/collectivistic orientation, where the solitary traveler represents the first and the group or package tourist represents the latter (Mehmetoglu, 2004). The values that lie at the heart of decision making, however, are not necessarily consistent and determining for all choices regarding experiences. At times a more collectivistic approach influences the experience choice, such as considerations of family or friends, whereas next time individual thinking and reasoning might be decisive factors. Motivation can as such differ from one time to the next and change as a result of experience. 
Relaxation is a feature of vacation motivation (e.g. Mehmetoglu, 2004). In Western societies, characterized by busy and hectic lifestyles, relaxation has gained an increased attention in experience promotion and consumption. Individualistic societies focus on the individual's need for regaining strength and balance in life, which can be attained by taking part in tourist experiences which provide relaxation (e.g. spa and wellness). Studies identify relaxation as motivation for hiking, connected to having a refreshing experience as well as enabling escape (Prentice \& Guerin, 1998). Assuming that this applies to nature-based experiences, the following hypothesis is suggested;

$\mathrm{H} 2 \mathrm{e}$ : Individualistic tourist nationalities perceive relaxation as more important than do their collectivistic counterparts.

Nature-based tourism experiences can also be a way of claiming an identity; hence experience participation becomes a sort of status symbol. The status aspect of an experience is signified by seeking recognition from the group for the experience in which one has taken part and one's own position (within the group) is then reinforced (e.g. Katz-Gerro, 2004). This reasoning implies that status at first glance seems to be more important to collectivistic nationalities.

$\mathrm{H} 2 \mathrm{f}$ : Collectivistic tourist nationalities perceive status as more important than do their individualistic counterparts.

Nature-based tourist experiences depend upon nature and attention to the valuation of nature is therefore necessary. Nature can be understood in different ways depending on national culture (e.g. Xu, Ding, \& Packer, 2008). Waitt et al. (2003, p. 541) found that "the human/nature binary actively defines the boundaries of nature-based tourism". The boundaries, however, will not be the same for all. The apprehension of nature-based tourism experience in one country or culture might mean something different to others. Ones comprehension of nature and how one relates to it on a daily basis, will likely affect the degree to which nature is emphasized in a naturebased tourism context.
Even if nature is a resource of great value in forming tourism experiences, it might not be the only or most emphasized part of such experiences (e.g. Mehmetoglu, 2005). In individualistic societies there is an increased focus on the benefits of being fit and healthy, emphasized by outdoor interests and physical activity. This is a tendency that perhaps suggests a stronger interest in nature amongst individualistic tourist nationalities. Furthermore, an increased attention to nature from an ecological perspective, related to climate change and learning (e.g. Kachel \& Jennings, 2010) could strengthen this assumption.

$\mathrm{H} 2 \mathrm{~g}$ : Individualistic tourist nationalities perceive nature as more important than do their collectivist counterparts.

To experience new places and cultures as an element of exploration is often inherent in travel; however, most tourists also want a predictable outcome of their holiday experiences. They want something new, in unison with an assurance of a great experience. The tourist experience is as such a combination of novelty and familiarity (Selstad, 2007, p. 20). Landscapes or natural sights might represent a setting for experiencing novelty and something out of the ordinary. Beauty in nature might furthermore be connected to novelty, in that the apprehension of attractiveness changes depending on setting, location, time and social affiliations. The challenge that lies in the novelty of participation in new nature-based tourism experiences seems to be corresponding with the mentality of individualistic societies were there often is an expectation and recognition of those choosing to do so.

$\mathrm{H} 2 \mathrm{~h}$ : Individualistic tourist nationalities perceive novelty as more important than do their collectivistic counterparts.

As argued then, there can be various motivations influencing nature-based tourist experiences. The chosen activity might furthermore play a role in this, as it impacts upon the experience perception through the characteristics of the activity. Cultural 
The relationship between tourist nationality, cultural orientation and nature-based tourism experiences.

orientation could possibly be partly decisive for actual activity choice.

\subsubsection{Activity dimension}

In nature-based experiences the activity aspect can be important to some. The level of activity will vary from person to person, and activities are chosen on the basis of required physical skills and abilities. There might also be an overall difference in activity preference relating to nationality, as in many countries there are certain traditions for which physical outdoor activities people tend to participate in. The assumption is that depending on nationality, tourists who travel to Norway differ in terms of activity level, and in which nature-based tourism activities they participate in.

Relation to nature could possibly explain differences and similarities in choice of naturebased activities. De Mooij (2005, p. 59) refers to three basic types of relationship to nature that are likely to differ according to national culture: (1) mastery over nature, (2) harmony with nature, and (3) subjugation to nature. Assuming then, that the relationship to nature varies according to nationality, the type of activity chosen will vary according to which of these relations are embrased. If, for example, mastery over nature is the goal, the activity will be more superficial and aimed at mastering a series of skills supporting a man against nature attitude. On the other hand, harmony with nature is sought through activities dependent upon nature and which at the same time provide a feeling of belonging to nature, e.g. river canoeing (see Mullins, 2009). There is not much research supporting the suggested differences in terms of activity preferences, hence the issue is explored drawing upon logical assumptions regarding nature-based tourism activities representative of various approaches to nature.

Hiking is a popular activity and is a common leisure pursuit in, for instance, the Nordic countries. It has a sense of individuality about it, as it does not necessarily demand the company of others, nor any organization from a provider. Studies show that hiking can represent relaxation, and can be exertiondriven (Prentice \& Guerin, 1998, p. 189). Hiking can therefore signify individual independence and freedom as well as challenge through physical exercise, as valued ideologies of more individualistic cultures.

$\mathrm{H} 2 \mathrm{i}$ : Individualistic tourist nationalities take more interest in hiking than do their collectivistic counterparts.

The activity of whale watching and whaling are in some countries carried out simultaneously, and naturally it causes continued debate (Higham \& Lusseau, 2008). Whale watching can to some be an activity closely connected to interest in the protection of whales. But participation can also be due to chance, as the activity happens to be available at the visited destination (op.cit). In the latter case there is a clear social aspect of being on a whale safari, spending quite some time on the boats without necessarily seeing whales. What is more, whale safari is perhaps less available (in an everyday setting) and hence seems more exotic to tourists in countries from the collectivistic end of the continuum, assuming then that the activity appeals more to those tourists.

$\mathrm{H} 2 \mathrm{j}$ : Collectivistic tourist nationalities take more interest in whale safari than do their individualistic counterparts.

Fishing is both a leisure pursuit and a livelihood, and as a tourism product it has gained popularity as a group experience. Fishing tourists in Norway mostly travel in groups (Hallenstvedt \& Wulff, 2002), and marine fishing has a social dimension as it is inclusive and normally conducted with friends and family (Normann, 2008, p. 239). Tourism fishing in Norway is often promoted towards men and in tourism context signifies companionship and a social activity for male bonding and friendship (Vespestad, 2010). 70 $\%$ of fishing tourists in Norway are typical "guys' only trips" (www.lu.no, 2010). Additionally the distinction between men and women is perhaps more obvious in collectivistic oriented countries, and referring to the above then one could assume that fishing appeals more to tourists from those countries. 
H2k: Collectivistic tourist nationalities take more interest in fishing than do their individualistic counterparts.

River rafting has gained popularity in the nature-based tourism experience market, and has turned out to be a successful product at many destinations. The initial impression is that of a social activity, as people maneuver the raft together. Looking at river rafting as an extraordinary experience (Arnould \& Price, 1993), however, it might be suggested that the activity appeals even more to tourists at the individualistic end of the continuum. Conquering nature, challenging oneself in paddling down river streams, and mastering the potential dangers of the activity, caters for the needs of individualists.

$\mathrm{H} 2 \mathrm{l}$ : Individualistic tourist nationalities take more interest in river rafting than do their collectivistic counterparts.

Based on the theoretical implications and the presented hypotheses then, the study was carried out to shed light on tourists' perception of nature-based experiences.

Table 1. Sample profile

\begin{tabular}{|c|c|c|c|c|c|}
\hline Variable & $\mathbf{N}$ & $\%$ & Variable & $\mathbf{N}$ & $\%$ \\
\hline Gender & & & Travel frequency & & \\
\hline Female & 345 & 51 & Every other year or more seldom & 47 & 7 \\
\hline Male & 316 & 46 & 1 a year & 202 & 30 \\
\hline \multirow[t]{2}{*}{ Missing } & 18 & 3 & 2-3 times a year & 344 & 51 \\
\hline & & & 4 times a year + & 64 & 10 \\
\hline Age & & & Holiday length & & \\
\hline $1-19$ & 56 & 8 & $1-3$ days & 26 & 4 \\
\hline $20-30$ & 175 & 26 & 4-7 days & 145 & 21 \\
\hline $31-40$ & 153 & 23 & 8-13 days & 238 & 35 \\
\hline $41-50$ & 125 & 19 & 14-30 days & 214 & 31 \\
\hline $51-60$ & 107 & 16 & $31+$ days & 33 & 5 \\
\hline $61-100$ & 57 & 8 & & & \\
\hline Nationality & & & Spending (in Euro) & & \\
\hline Belgian & 8 & 1 & $0-100$ & 11 & 2 \\
\hline German & 77 & 11 & $101-300$ & 37 & 5 \\
\hline British & 31 & 5 & $301-600$ & 86 & 13 \\
\hline American & 23 & 3 & $601-900$ & 105 & 15 \\
\hline Italian & 71 & 10 & $901+$ & 398 & 59 \\
\hline Spanish & 60 & 9 & & & \\
\hline French & 38 & 6 & Self- defined traveller type & $\mathbf{N}$ & \\
\hline Dutch & 66 & 10 & Nature-seeker & 210 & \\
\hline Australian & 9 & 1 & Urban & 59 & \\
\hline Ukrainian & 12 & 2 & Activity seeker & 99 & \\
\hline Norwegian & 32 & 5 & Ecotourist & 39 & \\
\hline Swiss & 19 & 3 & Neither & 19 & \\
\hline Israeli & 5 & 1 & Individual traveller & 317 & \\
\hline Czech & 17 & 2 & Group tourist & 111 & \\
\hline Russian & 147 & 21 & & & \\
\hline Danish & 6 & 1 & Self-defined activity level & $\mathbf{N}$ & $\%$ \\
\hline Swedish & 29 & 4 & Inactive & 19 & 3 \\
\hline Chinese & 5 & 1 & Intermediate & 229 & 34 \\
\hline Finnish & 18 & 3 & Active & 311 & 46 \\
\hline Slovenian & 6 & 1 & Highly active & 97 & 14 \\
\hline Total & 679 & 100 & & & \\
\hline
\end{tabular}




\section{Methodology}

\section{Sampling}

Purposive sampling (De Vaus, 2004; Jennings, 2001) was chosen as it is suitable for obtaining a large number of respondents. Selfadministered questionnaires were directed at tourists who were still on vacation, because asking questions about experiences in retrospect could be problematic. The face-toface method was used as the researcher or an assistant handed out the questionnaires to tourists during the summer of 2009. Based on studies showing conspicuous features in Norwegian promotion material (Vespestad, 2010) locations were chosen with reference to the nature-based experiences' relation to fjords and mountains, as well as were international tourists were likely to be. A total of 679 questionnaires were used in the analysis. The sample characteristics are presented in table 1. Nationalities represented by less than five respondents were deleted from the analyzed sample.

\section{Measurement}

A questionnaire was designed drawing upon the works of Soares (2004), Pine and Gilmore (1999), Hofstede (1980, 1983, 1994a, 1994b, 2001; Hofstede \& Hofstede, 2005), Den Breejen (2007) and Mehmetoglu (2007a, 2007b). The questions and measurements were based on existing literature, hence were considered consistent with the purpose of the study. The questions relate to nature-based experiences, novelty and change, individualism/ collectivism, activities, travel characteristics and demographics.

This article does not aim to depict characteristics of cultures as a whole, or to generalize the findings to all people in a nation. Operationalization of culture in terms of individualism/collectivism is therefore limited to tourists who visit Norway. The items for the scale were based on Soares (2004), and adapted to the context of the current study. The items are as follows: 1) Individuals should sacrifice self-interest for the group (either at school or the work place). 2) Individuals should stick with the group even through difficulties. 3) Group welfare is more important than individual rewards. 4) Group success is more important than individual success. 5) Individuals should only pursue their goals after considering the welfare of the group. 6) Group loyalty should be encouraged even if individuals suffer. The Cronbach's Alpha measures the internal reliability in the evaluation of Likert scales (De Vaus, 2004, p. 185). A reliability test of the collectivism scale indicated a Cronbach's Alpha of .86. According to De Vaus (2004) it suggests very good internal consistency reliability for the

Table 2. The measured nature-based experience dimensions

\begin{tabular}{llc}
\hline Variable & Mean & Standard deviation \\
\hline Experience dimensions & & \\
Entertainment (to have fun) & 4.01 & 1.21 \\
Education (to learn something) & 3.89 & 1.21 \\
Aesthetics (attractive surroundings) & 4.20 & 1.22 \\
Escapism (to feel excitement) & 4.07 & 1.05 \\
Motivation dimensions & & \\
Relaxation (to mentally relax) & 3.98 & 1.23 \\
Status (to seek esteem from others) & 2.61 & 1.59 \\
Nature (to enjoy nature) & 4.75 & 0.69 \\
Novelty (to explore a new place) & 4.43 & 0.94 \\
Activity dimensions & $\%$ & \\
Hiking & 64 & \\
Whale safari & 43 & \\
Fishing & 19 & \\
River-rafting & 3 & \\
& & \\
\hline
\end{tabular}


scale with this sample.

Nature-based tourism experiences are measured by single items on the three dimensions; experience, motivation and activity, as pictured in Table 2. Based on the theoretical considerations of the dimensions constituting nature-based tourism experiences, single item measures seemed beneficial. The use of single items on concrete attributes such as beliefs, perceptions, intentions and satisfaction is recommended (Bergkvist \& Rossiter, 2007). Hence, drawing upon the works of Pine and Gilmore (1999) experiences are measured by one item on each of the four elements of an experience: entertainment, education, esthetics and escapism (ref. Figure 1). Motivation is measured by relaxation, social, nature and novelty. Whereas the activity dimension, is measured by asking the tourists whether they had taken part in hiking, whale safari, fishing, or river rafting.

The translation/back-translation process was followed to ensure language equivalence in the questionnaire (Roster, Albaum, \& Rogers, 2006 , p. 750). The questions were first translated from English into Russian and another person translated it back to English without knowing the original English version. The two English versions were then compared and adjusted to ensure the same meaning in the two languages. The way questions are asked can shape the answer in various ways (Schwartz, 1999), even more so when addressing international tourists. For most of the respondents the questionnaire was not in their native language, and that might cause misunderstandings in the interpretation of questions. To attend to this potential flaw, the questionnaire was pre-tested on non-native English speakers and was adjusted accordingly. The language was simplified to make it easy to understand and closed response format was chosen because it is easier to comprehend for respondents who are not confident writing in a second language.

\section{Data analysis and results}

\section{Segmenting the nationalities}

In order to segment the different nationalities in the sample based on their cultural orientation (i.e. collectivism/individualism) using SPSS we conducted a CHAID (Chi Square Automatic Interaction Detection) analysis. CHAID is an analytical technique which, based on a combination of one single or several independent variables, divides the data into exclusive and exhaustive segments which differ with respect to the dependent variable (Dubinsky, Nataraajan, \& Huang, 2005; Van Diepen \& Franses, 2006).

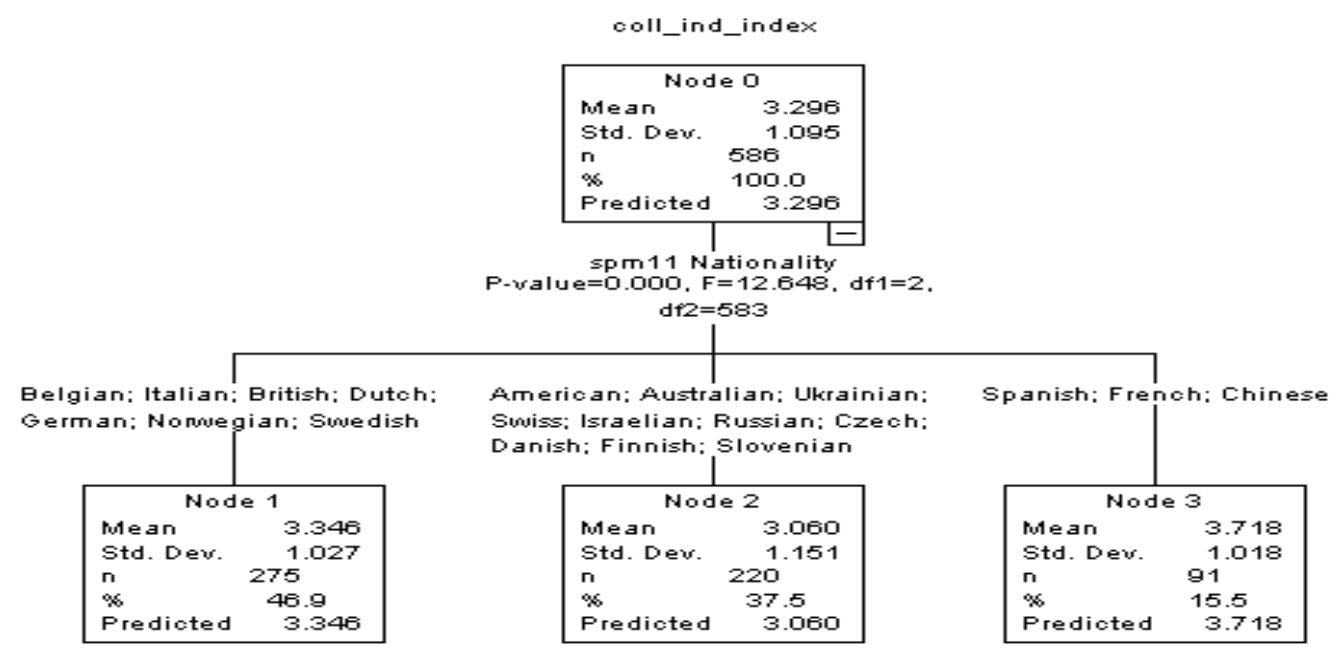

Figure 2. Chaid Analysis 
According to the results from the CHAID analysis (figure 2), the 20 different nationalities could be classified into three exclusive segments depending on their average score on the collectivism-individualism continuum (C-IC). Starting with the whole sample, it had an average score of 3.29 on the C-I-C whereas segment 1 , segment 2 , and segment 3 had scores of $3.34,3.06$ and 3.71 respectively. Since segment 2 was the lowest and segment 3 was the highest on the $\mathrm{C}-\mathrm{I}-\mathrm{C}$, we labelled segment 2 the individualistic nations and segment 3 the collectivistic nations whereas segment 1 scoring medium on the $\mathrm{C}-\mathrm{I}-\mathrm{C}$ was labelled as the IND-COLL nations.

Segment 1 (IND-COLL), $\quad$ Segment 2 (individualistic) and segment 3 (collectivistic) constituted 47, 37.5 and 15.5 percent of the sample respectively. According to the CHAID analysis in the current work individualistic nationalities included American, Australian, Ukrainian, Swiss, Israeli, Russian, Czech,
Danish, Finnish, and Slovenian. On the other hand, the collectivistic nationalities were Spanish, French and Chinese. Finally, the INDCOLL segment included the following nationalities: Belgian, Italian, British, Dutch, German, Norwegian, and Swedish. Based on the results from the CHAID analysis, we could conclude that $\mathrm{H} 1$ of the study was supported in that nationalities statistically differed based on their cultural orientation (i.e. collectivism/ individualism).

\section{Comparing the resulting segments}

In order to compare the resulting three segments based on an evaluation of their nature-based tourism experience, we employed MANOVA (Multivariate Analysis of Variance). MANOVA is a technique recommended when the purpose, as was the case in this study, is to examine an overall group difference based on a combination of conceptually related dependent variables/constructs (see for instance Hair, Black, Babin, Anderson, \&

Table 3. Mean ratings of nature-based tourism experience items by collectivistic, individualistic and IND-COLL seaments

\begin{tabular}{|c|c|c|c|c|}
\hline \multirow[b]{2}{*}{$\begin{array}{l}\text { Nature-based tourism experience } \\
\text { items }\end{array}$} & \multicolumn{3}{|c|}{ Segments } & \multirow[b]{2}{*}{$\begin{array}{l}\text { Significance difference } \\
\text { test } \\
\text { (with one-tailed p-values) }\end{array}$} \\
\hline & 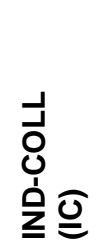 & $\begin{array}{l}.00 \\
. \frac{0}{\pi} \\
\frac{\pi}{2} \\
. \frac{0}{2} \\
: \frac{2}{0} \\
\stackrel{=}{=}\end{array}$ & 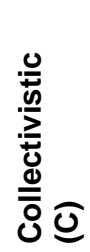 & \\
\hline Entertainment (to have fun) & 4.21 & 3.69 & 4.13 & $\mathrm{I}<\mathrm{C}^{\star \star \star *} ; \mathrm{I}<\mathrm{IC} * \star \star$ \\
\hline Learning (to learn something) & 3.72 & 4.14 & 3.76 & $\left|>C^{\star \star \star} ;\right|>\mid C^{\star \star \star}$ \\
\hline Asthetic (attractive surrounding) & 4.02 & 4.38 & 4.29 & $\mathrm{I}>\mathrm{I} \mathrm{C}^{\star \star \star} ; \mathrm{C}>\mathrm{I} \mathrm{C}^{\star \star}$ \\
\hline Escapism (to feel excitement) & 3.97 & 4.21 & 3.99 & $|>C * \star ;|>\mid C^{\star \star \star}$ \\
\hline Relaxation (to mentally relax) & 3.92 & 4.11 & 3.89 & $\left|>C^{*} ;\right|>\mid C^{* *}$ \\
\hline Status (to seek esteem from others) & 2.62 & 2.43 & 3.02 & $\mathrm{I}<\mathrm{C}^{\star \star *} ; \mathrm{I}<\mathrm{IC} *$ \\
\hline Nature (to enjoy nature) & 4.73 & 4.81 & 4.67 & $|>C * * ;|>\mid C^{*}$ \\
\hline Novelty (to explore a new place) & 4.28 & 4.60 & 4.51 & $\mathrm{I}>\mathrm{I} \mathrm{C}^{\star \star *} ; \mathrm{C}>\mathrm{I} \mathrm{C}^{\star \star}$ \\
\hline Hiking & 0.52 & 0.80 & 0.65 & $I>C^{\star \star *} ;|>| C^{\star \star *} ; C>I C^{*}$ \\
\hline Whale safari & 0.56 & 0.30 & 0.40 & $\mathrm{I}<\mathrm{C}^{\star \star *} ; \mathrm{I}<\mathrm{I} \mathrm{C}^{\star \star *} ; \mathrm{C}<\mathrm{I} \mathrm{C}^{\star \star *}$ \\
\hline Fishing & 0.28 & 0.12 & 0.11 & $\mathrm{I}<\mathrm{I} \mathrm{C}^{\star \star *} ; \mathrm{C}<\mathrm{I} \mathrm{C}^{\star \star \star}$ \\
\hline River-rafting & 0.04 & 0.02 & 0.03 & No significant differences \\
\hline
\end{tabular}

Items in bold represent experience dimensions; Items in italic represent travel motives; the remaining items refer to travel activities

* $p<.10 \quad$ ** $p<.05 \quad$ *** $p<.01$ 
Tatham, 2006). Whether an overall group difference, based on a set of dependent variables, exists or not is then decided by an omnibus test (F-test).

In the current work, the conceptually related dependent variables were the travel motivation, travel experience, and travel activity which in tandem constituted the overarching construct of 'nature-based tourism experience', whereas the groups were the collectivistic, individualistic and IND-COLL segments. The omnibus tests (Pillai's Trace, Wilks' Lambda, Hotelling's Trace, and Roy's Largest Root) were all significant at the 0.01 level, indicating that the collectivistic, individualistic and IND-COLL nationalities statistically differed based on an evaluation of their nature-based tourism experience. Thus, $\mathrm{H} 2$ of the study was supported.

\section{Item differences between the segments}

The significant overall MANOVA test was followed up by a univariate analysis of variance (ANOVA) whose purpose is to separately detect the dependent variables in terms of which of the groups statistically differ.

As shown in table 3, the collectivistic nationalities placed a higher importance on the entertainment (experience) and status (motive) dimensions than did the individualistic nationalities. As far as travel activities were concerned, a larger proportion of the collectivists indicated that they had participated in whale-safari activity as compared to the individualists. On the other hand, the individualists considered learning and escapism (experience), relaxation and nature (motive) more salient than did the collectivists. Furthermore, the results indicated that a larger share of the individualists had participated in the activity of hiking in comparison with the collectivists.

Furthermore, the study results showed that the IND-COLL nationalities placed statistically less importance on aesthetic, novelty, and hiking dimensions than did the collectivists and individualists. The IND-COLL group also considered learning, escapism, relaxation and nature dimensions less important as opposed to the individualists. Moreover, the IND-COLL segment placed statistically more salience on entertaintment and status items than did the individualists. Finally, a larger proportion of the IND-COLL segment had participated in the activities of whale safari and fishing as compared to both the individualists and collectivists.

\section{Discussion}

The article adheres to a dynamic view of the relationship between cultural orientation and nature-based tourism experience perceptions, suggesting movement along a collectivismindividualism continuum. Even though tourists from various countries differ, globalization tendencies might bring about more similar consumption patterns. Nevertheless, in the current study there is an observed diversity in the way tourists from different countries behave and act when taking part in nature-based experiences.

$\mathrm{H} 1$ is confirmed, hence there is a significant relationship between nationality and cultural orientation. $\mathrm{H} 2$ proves a difference in the perception of nature-based tourism experiences between collectivistic and individualistic tourist nationalities. Moreover, nature-based tourism experiences are analyzed in terms of three dimensions: experience, motivation and activity. The individualistic and collectivistic oriented tourists proved different on all three dimensions. The difference between tourists' nationality then, supports findings showing difference in service perception (Hsieh \& Tsai, 2009). It is essential to elaborate on where the significant differences between the segments lie.

Individualistic nationalities place higher importance on nature $(\mathrm{H} 2 \mathrm{~g})$ than their collectivistic counterparts, corresponding well with their emphasis on learning $(\mathrm{H} 2 \mathrm{~b})$. It indicates a difference among the two segments, confirming that learning about natural phenomena and wildlife is stressed by individualists (ref. Wen \& Ximing, 2008). Individualists' emphasis on knowledge, moreover, supports the study of British overseas travelers (Cheong, et al., 2002). On the other hand, collectivistic nationalities place 
less importance on nature, possibly because of more interest in the social aspect of naturebased experiences; hence a nature setting is secondary to them.

Experiences can also be entertainment (Pine \& Gilmore, 1999), and it proves more important to collectivistic nationalities $(\mathrm{H} 2 \mathrm{a})$. The magnitude of entertainment could furthermore indicate interest in fun and enjoyment, without necessarily demanding a specific level of skill or competence. To be entertained for the sake of amusement might, in part, be due to less available leisure time for collectivistic nationalities in general; hence mere recreation is sought from nature-based tourism experiences. Emphasis placed on entertainment also seems to correspond with collectivistic nationalities' participation in whale safari, because the activity does not demand specific skills or competences. Furthermore, tourists in the collectivistic segment are perhaps less likely to be involved in the controversies related to whaling and whale watching.

Individualistic nationalities place greater importance on escapism than their collectivistic counterparts $(\mathrm{H} 2 \mathrm{c})$; quite possibly illustrating a valuation of nature-based tourism experiences more in terms of activities in nature rather than nature in itself. Escapism can be related to extraordinary experiences, represented by harmony with nature, personal growth and renewal (see Arnould \& Price, 1993). The link to hiking, therefore, seems evident $(\mathrm{H} 2 \mathrm{i})$, as hiking offers the opportunity to immerse in nature, and the possibility for physical and sustainable use of nature. This is in coherence with studies connecting hiking and relaxation (e.g. Prentice \& Guerin, 1998). The social character of hiking allows social reassurance in being together, perhaps pointing towards a new sort of collectivism (ref. Guneriussen, 2010), as individualistically oriented tourists might seek events and short-term acquaintances, offering a socio-cultural community with other hikers.

Furthermore, relating activities to the views of nature (ref. De Mooij, 2005), hiking seems associated to harmony with nature, and is most important to individualistic nationalities. Moreover, it is consistent with their emphasis on nature. River rafting is mastery of nature as it clearly represents a high involvement activity. There is, however, no significant difference between the segments in rafting participation, hence $\mathrm{H} 2 \mathrm{l}$ is rejected. Finally, subjugation to nature resembles the exploration aspect of whale safari, and is favored by collectivistic tourist nationalities (H2j).

Taking part in nature-based tourism experiences can, to some, in part, be due to seeking recognition from their peers. The status aspect of nature-based tourism experiences is more important to the collectivistic nationalities ( $\mathrm{H} 2 \mathrm{f})$, as they seek to reinforce their own position within the group (ref. Katz-Gerro, 2004). Moreover, regardless of level of physical challenge, nature-based tourism experiences can offer relaxation. The relaxation aspect is more important to the individualistic nationalities $(\mathrm{H} 2 \mathrm{e})$. This could be a result of getting away from a stressful everyday life or due to an increased need for physical activity or outdoor experiences as many jobs are no longer as physically challenging. Both relaxation and prestige are socio-psychological motivations, whereas novelty and education are destination attributes (Crompton, 1979). Hence, if knowledge is sought by individualistic nationalities it is a feature that could be emphasized as a destination attribute, to attract such tourists.

There are no significant differences between the individualistic and collectivistic segments with reference to aesthetics and novelty; hence, $\mathrm{H} 2 \mathrm{~d}$ and $\mathrm{H} 2 \mathrm{~h}$ are rejected. In addition, $\mathrm{H} 2 \mathrm{k}$ referring to fishing is rejected as no significant differences are identified when comparing the individualistic and collectivistic segments. As it turns out, Eastern European countries (e.g. Russia, the Ukraine, Slovenia), assumed to be at the collectivistic end of the continuum, fall into the individualistic category. It indicates a move towards and even beyond some Western European countries in terms of individualism. This in a sense supports the statement that former collectivistic values are gradually being replaced by individualistic values through the exposure to western brands and advertising (see Fernandez, Carlson, Stepina, \& Nicholson, 1997; Manrai, et al., 
2001, p. 270). Moreover, it might point towards a shift where tourists from highly individualistic cultures now move towards a new sense of collectivism, providing a short-term feeling of group membership (Guneriussen, 2010). Taking part in a common experience for a limited time period leads to a sense of community even if the experience itself represents individualistic values.

With reference to the above discussion one needs to be aware that the individualismcollectivism orientation might be moderated by for instance age or gender (see e.g. Manrai, et al., 2001; Oh, et al., 2004, p. 317), suggesting young people could adapt more quickly to change. As a result of the rapid changes in Eastern Europe the value set of young people in Eastern and Western Europe might also become more similar (Schwartz \& Bardi, 1997, p. 407).

In nature-based tourism experiences the relationship between activity participation, motivation, cultural orientation and nationality seems evident. A memorable nature-based tourism experience is first created when the various dimensions forming the experience are developed to meet the demands of the tourist's valuation of those components.

\section{Conclusion}

This article segments tourists' nationality in terms of cultural orientation, and compares the segments' perception of nature-based tourism experiences. The different dimensions of a nature-based experience are valued in dissimilar ways depending on where a nationality is placed along the collectivism individualism continuum. The study shows that the core elements of nature-based tourism experiences are not equally important to the three segments; collectivistic, individualistic and IND-COLL. A main point of interest is that nature as such proves less important to the collectivistic segment than to the individualistic segment, however, the collectivist segment do value e.g. entertainment more. The IND-COLL segment is a mid-category and hence was not the main focus of attention, for the same reason it is not thoroughly commented upon in the discussion. To summarize then, $\mathrm{H} 1$ and $\mathrm{H} 2$ is supported, as well as $\mathrm{H} 2 \mathrm{a}, \mathrm{H} 2 \mathrm{~b}, \mathrm{H} 2 \mathrm{c}, \mathrm{H} 2 \mathrm{e}$, $\mathrm{H} 2 \mathrm{f}, \mathrm{H} 2 \mathrm{~g}, \mathrm{H} 2 \mathrm{i}$ and $\mathrm{H} 2 \mathrm{j}$ proves significant differences between the most individualistic and most collectivistic group. On the contrary hypotheses $\mathrm{H} 2 \mathrm{~d}, \mathrm{H} 2 \mathrm{~h}, \mathrm{H} 2 \mathrm{k}$ and $\mathrm{H} 2 \mathrm{l}$ are rejected, with no significant differences between these groups.

The differences in valuation of nature-based tourism experience dimensions offer both practical and theoretical implications. For instance, in terms of the need for adapting promotion with reference to tourist nationalities' preferences, one way of segmenting nationalities could be according to cultural orientation. Moreover, the study calls attention to globalization as an initiator to change in tourism markets, however, does not imply that all tourists eventually will have similar preferences because of it. What is more, tourism experience choices could also be affected by personality, but as it is a complicated segmentation variable of international tourists it is perhaps more fruitful for researchers and marketers alike to use a more general approach. Moreover, naturebased tourism experiences require awareness of not only individual's perceptions, but also of the simultaneous and collective coconsumption that is taking place. This study thus shows that countries can be segmented in terms of cultural orientation, and that they do differ in terms of nature-based tourism experiences evaluation.

\section{Limitations}

Purposive sampling is not representative of the population, and the external validity is, therefore, limited as findings cannot be generalized. Furthermore, the temporal frame of the data might affect the outcome as it concerns tourists visiting Norway in the summer season. The choice of locations and the selection procedures at the locations could potentially cause biased data, resulting in an overrepresentation of a certain type of people, i.e. those that the researcher feels most comfortable approaching (Jennings 2001). What is more, the subjective manner of the Likert scale format raises issues such as translation errors, differences in response style, and the reference group effect that might 
The relationship between tourist nationality, cultural orientation and nature-based tourism experiences.

influence the comparison and outcome of the study (Heine, Lehman, Peng, \& Greenholtz, 2002). Moreover, evaluation on Likert scales can be problematic because people from different cultures adopt different standards when evaluating themselves, thus the comparison of nationalities might conceal the very cultural difference (Heine, et al., 2002). Nevertheless, the researchers are aware of these potential flaws and have, therefore, aimed at taking necessary precautions.

\section{Further implications}

Practical implications of this study point towards the potential benefits for companies that lies in adapting promotion towards clusters of nationalities, based on tourists' nature-based experience perceptions. A C-I-C segmentation might be useful for tourism marketers as a broader way of segmenting the market than by nationality only. The study also vindicates the need to develop management tools applicable in a cross-cultural context to better accommodate to the differing tourists expectations. Based on knowledge of what the various kinds of tourists emphasize and how they co-experience, tools or guidelines for memorable nature-based tourism experiences might be formed. In a service perspective one might, furthermore, use these findings to accommodate to the various spheres of interests of international tourists who are likely to be taking part in nature-based tourist experiences.

\section{References}

Arnould, E. J., \& Price, L. L. (1993). River Magic Extraordinary experience and the extended service encounter. Journal of Consumer Research, 20(1), 24-45.

Balmford, A., Beresford, J., Green, J., Naidoo, R., Walpole, M., \& Manica, A. (2009). A global perspective on trends in nature-based tourism. PLoS Biology, 7(6), 1-6.

Beard, J. G., \& Ragheb, M. G. (1983). Measuring leisure motivation. Journal of Leisure Research, 15(3), 219-228.

Beedie, P., \& Hudson, S. (2003). Emergence of mountain-based adventure tourism. Annals of Tourism Research, 30(3), 625-643.

Bergkvist, L., \& Rossiter, J. R. (2007). The predictive valitdity of multiple-item versus single-item measures of the same constructs. Journal of Marketing Research, XLIV(May), 175184.

Bitner, M. J. (1992). Servicescapes - The impact of physical surroundings on customers and employees. Journal of Marketing, 56(2), 5771.

Björk, P. (2000). Ecotourism from a conceptual perspective, an extended definition of a unique tourism form. The International Journal of Tourism Research, 2(3), 189202.

Caruana, R., Crane, A., \& Fitchett, J. A. (2008). Paradoxes of consumer independence: $A$ critical discourse analysis of the independent traveller. Marketing Theory, 8(3), 253-272.

Cayla, J., \& Arnould, E. J. (2008). A cultural approach to branding in the global marketplace. Journal of International Marketing, 16(4), 86-112.

Celsi, R. L., Rose, R. L., \& Leigh, T. W. (1993). An exploration of high-risk leisure consumption through skydiving. Journal of Consumer Research, 20(1), 1-23.

Cheong, S., Jang, S., \& Liping, C. A. (2002). Travel motivations and destination choice: A study of British outbound market. Journal of Travel \& Tourism Marketing, 13(3), 111133.

Cooper-Martin, E. (1991). Consumers and movies Some findings on experiential products. Advances in Consumer Research, 18, 372378.

Crompton, J. L. (1979). Motivations for pleasure vacation. Annals of Tourism Research, 6(4), 408-424.

Csikszentmihalyi, M., \& Rathunde, K. (1993). The measurement of flow in everyday life: Toward a theory of emergent motivation. Nebraska Symposium on Motivation, 40, 57-97.

De Mooij, M. K. (2005). Global marketing and advertising: Understanding cultural paradoxes (2nd ed.). Thousand Oaks, California: Sage.

De Mooij, M. K., \& Hofstede, G. (2010). The Hofstede model. Applications to global branding and advertising strategy and research. International Journal of Advertising, 29(1), 85-110.

De Vaus, D. A. (2004). Surveys in social research (5th ed.). London: Routledge.

Den Breejen, L. (2007). The experiences of long distance walking: A case study of the West Highland way in Scotland. Tourism Management, 28(6), 1417-1427.

Dubinsky, A. J., Nataraajan, R., \& Huang, W.-Y. (2005). Consumers' moral philosophies: 
Identifying the idealist and the relativist. Journal of Business Research, 58(12), 1690-1701.

Fernandez, D. R., Carlson, D. S., Stepina, L. P., \& Nicholson, J. D. (1997). Hofstede's country classification 25 years later. Journal of Social Psychology, 137(1), 43-54.

Galloway, G. (2002). Psychographic segmentation of park visitor markets: Evidence for the utility of sensation seeking. Tourism Management, 23(6), 581-596.

Guneriussen, W. (2010). Social change and shifting conceptions of nature. The coming of "adventure society"? Working paper, unpublished by May 2010.

Hair, J. F., Black, W. C., Babin, B. J., Anderson, R. E., \& Tatham, R. L. (2006). Multivariate data analysis (6th ed.). New Jersey: Prentice Hall.

Hallenstvedt, A. \& Wulff, I. (2002). Turistfiske som inntektskilde. (Tourist fishing as a source of income, my translation). Report prepared for Innovation Norway. Norwegian College of Fishery Science and University of Tromsø. Retrieved July 20, 2010, from http://home.samf.norut.no/frank/Fisketurism e/relevante\%20dokumenter/Turistfiske\%20 som\%20inntektskilde.pdf

Heine, S. J., Lehman, D. R., Peng, K., \& Greenholtz, J. (2002). What's wrong with cross-cultural comparisons of subjective Likert scales?: The reference-group effect. Journal of Personality and Social Psychology, 82(6), 903-918.

Herrmann, A., \& Heitmann, M. (2006). Providing more or providing less? Accounting for cultural differences in consumers' preference for variety. International Marketing Review, 23(1), 7-24.

Higham, J. E. S., \& Lusseau, D. (2008). Slaughtering the goose that lays the golden eggs: Are whaling and whale-watching mutually exclusive? Current Issues in Tourism, 11(1), 63-74.

Hofstede, G. (1980). Motivation, leadership, and organization: Do American theories apply abroad? Organizational Dynamics, Summer, 42-63.

Hofstede, G. (1983). National cultures in four dimensions. A research-based theory of cultural differences among nations. International studies of management and organization, XIII(1-2), 46-74.

Hofstede, G. (1984). Culture's consequences: International differences in work related values (Abridged edition Vol. 5). Newbury Park, California: Sage Publications.
Hofstede, G. (1994a). The business of international business is culture. International Business Review, 3(1), 1-14.

Hofstede, G. (1994b). Cultures and organizations: Software of the mind (paperback edition). London: McGraw-Hill.

Hofstede, G. (2001). Culture's consequences comparing values, behaviors, institutions, and organizations across nations (2nd ed.). Thousand Oaks, California: Sage.

Hofstede, G., \& Hofstede, G. J. (2005). Cultures and organizations: Software of the mind (2nd ed.). New York: McGraw-Hill.

Hsieh, A.-T., \& Tsai, C.-W. (2009). Does culture really matter? Hotel service perceptions by Taiwan and American tourists. International Journal of Culture, tourism and hospitality research, 3(1), 54-69.

Jennings, G. (2001). Tourism research. Milton, Qld.: Wiley Australia.

Kachel, U. Jennings, G. (2010). Exploring tourists' environmental learning, values and travel experiences in relation to climate change: $\mathrm{A}$ postmodern constructivist research agenda. Tourism and Hospitality Research, 10(2), 130-140.

Katz-Gerro, T. (2004). Cultural consumption research: Review of methodology, theory, and consequence. International Review of Sociology, 14(1), 11-29.

Kozak, M. (2002). Comparative analysis of tourist motivations by nationality and destinations. Tourism Management, 23(3), 221-232.

Lang, C.-T., \& O'Leary, J. T. (1997). Motivation, participation, and preference: A multisegmentation approach of the Australian nature travel market. Journal of Travel \& Tourism Marketing, 6(3/4), 159-180.

Lee, S.-H., \& Sparks, B. (2007). Cultural influences on travel lifestyle: A comparison of Korean Australians and Koreans in Korea. Tourism Management, 28(2), 505-518.

Manrai, L. A., Lascu, D.-N., Manrai, A. K., \& Babb, H. W. (2001). A cross-cultural comparison of style in Eastern European emerging markets. International Marketing Review, 18(3), 270-285.

Mehmetoglu, M. (2004). A typology of tourists from a different angle. International Journal of Hospitality and Tourism Administration, 5(3), 69-89.

Mehmetoglu, M. (2007a). Nature-based tourism: A contrast to everyday life. Journal of Ecotourism, 6(2), 111-126.

Mehmetoglu, M. (2007b). Typologising nature-based tourists by activity - Theoretical and practical implications. Tourism Management, 28(3), 651-660. 
The relationship between tourist nationality, cultural orientation and nature-based tourism experiences.

Mossberg, L. (2007). A marketing approach to the tourist experience. Scandinavian Journal of Hospitality and Tourism, 7(1), 59-74.

Mullins, P. M. (2009). Living stories of the landscape: Perception of place through canoeing in Canada's North. Tourism Geographies, 11(2), 233-255.

Ng, S. I., Lee, J. A., \& Soutar, G. N. (2007). Tourists' intention to visit a country: The impact of cultural distance. Tourism Management, 28(6), 1497-1506.

Normann, Ø. (2008). Marine fishing tourism in Lofoten, Northern Norway: the management of the fish resources. In B. Lovelock (Ed.), Tourism and the Consumption of Wildlife: Hunting, shooting and sport fishing (pp. 239-253). New York: Routledge.

Nyaupane, G. P., Morais, D. B., \& Graefe, A. R. (2004). Nature tourism constraints - A cross-activity comparison. Annals of Tourism Research, 31(3), 540-555.

O'Dell, T. (2007). Tourist experiences and academic junctures. Scandinavian Journal of Hospitality and Tourism, 7(1), 34-45.

Oh, J. Y.- J., Cheng, C.- K., Lehto, X. Y., \& O'Leary, J.T. (2004). Predictors of tourists' shopping behaviour: Examination of sociodemographic characteristics and trip typologies. Journal of Vacation Marketing, 10(4), 308-319.

Pine, B. J., \& Gilmore, J. H. (1999). The experience economy, Work is theatre \& every business a stage. Boston, Massachusetts: Harvard Business School Press.

Prebensen, N. K. (2006). A grammar of motives for understanding individual tourist behaviour. Norwegian School of Economics and Business Administration: Bergen.

Prentice, R., \& Guerin, S. (1998). The romantic walker? A case study of users of iconic Scottish landscape. Scottish Geographical Magazine, 114(3), 180-191.

Preston-Whyte, R. (2002). Construction of surfing space at Durban, South Africa. Tourism Geographies, 4(3), 307-328.

Rhodes Espinoza, A., R. (2008). Motivation for Nature Tourism. www.ecotourismlatino.com

Roster, C., Albaum, G., \& Rogers, R. (2006). Can cross-national/cultural studies presume etic equivalency in responclents' use of extreme categories of Likert rating scales? International Journal of Market Research, 48(6), 741-759.
Schwartz, N. (1999). Self-reports. How the questions shape the answers. American Psychologist, 54(2), 93-103.

Schwartz, S. H., \& Bardi, A. (1997). Influences of adaptation to communist rule on value priorities in Eastern Europe. Political Psychology, 18(2), 385-410.

Selstad, L. (2007). The social anthropology of the tourist experience. Exploring the "Middle Role". Scandinavian Journal of Hospitality and Tourism, 7(1), 19-33.

Soares, A. M. (2004). The influence of culture on consumers: Exploratory and risk taking behaviour. University of Minho.

Steenkamp, J.-B., E. M. . (2001). The role of national culture in international marketing research. International Marketing Review, 18(1), 3044.

Stilling Blichfeldt, B. (2007). A nice vacation: Variations in experience aspirations and travel careers. Journal of Vacation Marketing, 13(2), 149-164.

Van Diepen, M., \& Franses, P. H. (2006). Evaluating chi-squared automatic interaction detection. Information Systems, 31(8), 814-831.

Vespestad, M. K. (2010). Promoting Norway abroad: A content analysis of photographic messages of nature-based tourism experiences. Tourism, Culture and Communication (forthcoming).

Waitt, G., Lane, R., \& Head, L. (2003). The boundaries of nature tourism. Annals of Tourism Research, 30(3), 523-545.

Wen, Y., \& Ximing, X. (2008). The difference in ecotourism between China and the West. Current Issues in Tourism, 11(6), 567-586.

World Tourism Organization, UNWTO. (2010) International tourism on track for a rebound after an exceptionally challenging 2009. Retrieved April 28, 2010, from http://www.unwto.org/ media/news/en/press_det.php?id=5361

Xu, H., Ding, P., \& Packer, J. (2008). Tourism research in China: Understanding the unique cultural contexts and complexities. Current Issues in Tourism, 11(6), 473-491.

www.lu.no. Turistfiske skaper vekst [Fishing tourism creates growth, my translation] (n.d.) Retrieved July 20, 2010, from http://www.lu.no/content/view/3175/125/ 